\title{
CONSIDERAÇÕES A RESPEITO DA RETOMADA CARNAVALESCA O CARNAVAL DE RUA NO RIO DE JANEIRO
}

\author{
Jorge Edgardo Sapia (Unesa) \\ Andréa Almeida de Moura Estevão (Unesa)
}

O trabalho contextualiza e indica os atores que estão na base da retomada carnavalesca na cidade do Rio de Janeiro. A ideia de festa carnavalesca leva a pensar as disputas em torno do espaço público. Walter Benjamin é o autor que nos permite transitar nessa rede de reconhecimento e de reapropriação da cidade enquanto espaço comum e democrático. Ao valorizar a felicidade, o autor oferece pistas e brechas que tornam possivel, ou pelo menos desejável, elaborar questões que implicam a articulação de fragmentos do passado e do presente abrindo novos horizontes não apenas nem necessariamente analíticos.

\section{BLOCOS CARNAVALESCOS, ESPAÇO PÚBLICO, WALTER BENJAMIN, CARNAVAL.}

SAPIA, Jorge Edgardo; ESTEVÃO, Andréa Almeida de Moura. Considerações a respeito da retomada carnavalesca: o carnaval de rua no Rio de Janeiro. Textos escolhidos de cultura e arte populares, Rio de Janeiro, v.9, n.1, p. 57-76, mai. 2012. 


\section{CONSIDERATIONS REGARDING CARNAVAL'S RECOVERY}

THE STREET CARNAVAL IN RIO DE JANEIRO

Jorge Edgardo Sapia (Unesa)

Andréa Almeida de Moura Estevão (Unesa)

This paper contextualizes and indicates the actors that form the basis of the recovery of carnaval in the city of Rio de Janeiro. The idea of carnaval fosters the pondering about dispute over the public space. Walter Benjamin is the author who allows us to move in this network of recognition and re-appropriation of the city as both a common and a democratic space. By valuing happiness, the author offers hints and gaps that make possible, or at least desirable, to develop questions that involve the articulation of fragments of past and present - opening new horizons not exclusively or necessarily analytical.

\section{CARNAVAL, CARNAVAL GROUPS PUBLIC SPACE, WALTER BENJAMIN.}

SAPIA, Jorge Edgardo; ESTEVÃO, Andréa Almeida de Moura. Considerações a respeito da retomada carnavalesca: o carnaval de rua no Rio de Janeiro. Textos escolhidos de cultura e arte populares, Rio de Janeiro, v.9, n.1, p. 57-76, mai. 2012. 


\section{INTRODUÇÃO}

O carnaval de rua como festa popular é acontecimento e movimento que se defronta com questões pertinentes à disputa do espaço urbano que se entende como público. Essa forma de celebração põe necessariamente em pauta interrogações, ações e conflitos que a precisão da sabedoria popular enuncia na questão: quem, afinal, é o dono da rua? Essa pergunta, nem sempre formulada explicitamente, perpassa de forma latente o debate e as negociações em torno da realização da festa. A pergunta é profícua e permite múltiplas abordagens. Aqui, nos interessará situá-la no contexto do que denominamos "retomada do carnaval de rua" do Rio de Janeiro.

Nos primeiros anos do século XXI o carnaval de rua na cidade foi redescoberto por diversos atores que disputam a arena festiva: segmentos cada vez maiores da população jovem urbana; indústrias ligadas à área de hotelaria e turismo; a mídia que produz um olhar particular sobre o fenômeno; diversas marcas comerciais, em particular, da telefonia e do setor cervejeiro; além, é claro, do poder público. No Carnaval de 2012, por exemplo, o resultado da parceria entre estes dois últimos atores, resultou no loteamento da cidade por marcas comerciais que instauraram um carnaval monocromático, assinado e patrocinado numa "festa que precisa ser multicolorida, independente e autônoma".1

Como podemos observar a redescoberta vai expressar-se na emergência de tensões e conflitos decorrentes das diversas leituras e concepções de mundo que entram em contato por ocasião da festa. Papel central ocupam os atores que se foram apropriando da rua, participando ativamente nos diversos blocos carnavalescos que costuram a cidade, durante muito tempo apresentada como partida. As vozes discordantes dessa ocupação encontraram eco na editoria de cidade do jornal $O$ Globo que pauta e é pautada pelas cartas dos leitores. Há nesse espaço insistente leitura do carnaval pela perspectiva da desordem. A cobertura do jornal no Carnaval de 2011, por exemplo, foi pródiga na divulgação de imagens que dão destaque às posturas consideradas o problema principal da multidão desregrada na rua: foliões urinando nas ruas da cidade. Propostas no sentido de multar quem se estiver aliviando fora dos banheiros públicos nunca em número suficiente para atender à demanda crescente - e a própria voz de prisão àqueles flagrados em atitude "obscena" ${ }^{2}$ nos falam dessas tentativas autoritárias de resolução dos conflitos suscitados pela ocupação das ruas. Entretanto, se olharmos de outra perspectiva, podemos perceber que o carnaval aponta para o deficit de equipamentos urbanos capazes de atender às necessidades da população independentemente da festa carnavalesca. 
Por retomada carnavalesca entendemos, embora não exclusivamente, o surgimento, na década de 1980, de uma série de blocos, organizados principalmente na Zona Sul da cidade e fundadores, em 2000, da Associação Sebastiana, ${ }^{3}$ como resultado da necessidade de pensar o fenômeno do crescimento, dos impactos e consequências que a festa carnavalesca produz. Essa vontade associativa surge quando seus integrantes percebem que, além dos encontros simbólicos, a festa se transformava em arena, colocando em contato visões de mundo diferentes. Como sugere Cruells (2006, p.36), as festas:

Servem para que brotem as contradições e os antagonismos, as lutas e os conflitos que na vida cotidiana são quase imperceptíveis. Por isso a arena festiva resulta tão adequada para contemplar quais são as relações de poder numa sociedade, como interagem princípios ideológicos, concepções do passado com projetos de futuro que são, por definição, incompatíveis e que convivem postergando sua permanente tendência ao enfrentamento. ${ }^{4}$

Os primeiros versos do samba "Plataforma", de autoria de João Bosco e Aldyr Blanc - "não põe corda no meu bloco/nem vem com teu carro-chefe/não dá ordem ao pessoal"-, marcam o princípio de construção da identidade dos blocos "da retomada", posto que enunciam a vontade de estar junto com outros em liberdade, no espaço de heterogeneidade social e cultural característico das cidades modernas. O samba sugere, ainda, celebrar a alegria e espontaneidade com "passistas à vontade que não dancem minueto" e a possibilidade de olhar para a rua e a cidade como lugar de fruição, de encontros e de confrontos, de conhecimentos e reconhecimentos recíprocos; como um espaço no qual, como argumenta Lefebvre (1991), a prioridade do valor de uso se sobreponha à "orientação irreversível na direção do dinheiro, na direção do comércio, na direção das trocas, na direção dos produtos" que caracterizam o valor de troca no espaço urbano moderno. Henri Lefebvre considera em seu texto $O$ direito à cidade que

A própria cidade é uma obra, e esta característica contrasta com a orientação irreversível na direção do dinheiro, na direção do comércio, na direção das trocas, na direção dos produtos. Com efeito, a obra é valor de uso e o produto é valor de troca. O uso principal da cidade, isto é, das ruas e das praças, dos edifícios e dos monumentos, é a Festa (que consome improdutivamente sem nenhuma outra vantagem além do prazer e do prestígio, enormes riquezas em objetos e em dinheiro) (LEFEBVRE, 1991, p. 4).

E a festa pública nos fala de encontros e de conflitos que resultam das leituras divergentes sobre o uso e o direito à cidade. 


\section{DO CHOQUE DE ORDEM AO CHOQUE DE FOLIA}

Na cidade de Rio de Janeiro, o prefeito Eduardo Paes inicia sua gestão no mês de janeiro de 2009 prometendo um "choque de ordem". A orientação é de ordenar o setor de comércio informal e venda ambulante, representantes do que é considerado indisciplina urbana, e vai aos poucos intervindo em outros domínios.

Desde a gestão do prefeito Pereira Passos - responsável pelo processo de modernização no início do século XX - as preocupações com a ordem e a desordem estão colocadas. A necessidade de criar um espaço de sociabilidade burguesa encontra apoio e legitimidade em uma multiplicidade de discursos, de imagens e representações sobre a cidade, que coincidem com a vontade, das elites dominantes, de controle dos setores populares e de criação de um espaço de fruição tanto exclusivo quanto excludente. A ideia de uma cidade reformada física e moralmente pela ciência e pela indústria vai permitir eliminar as quebradas da vida e "governar por retas" (LEFEBVRE, 1991. CARVALHO, 1994). Sanitaristas, arquitetos, políticos e juristas fazem uso de um discurso ideológico que contrapõe dois mundos distintos: o da ordem e do trabalho, cujo espaço privilegiado é a fábrica e, do outro lado, o do cortiço e da rua, considerados espaços da desordem e do vício; do não trabalho (VALLADARES, 1991. SEVCENKO, 1983).

A consolidação da sociabilidade e da hegemonia burguesa, nesse período, redefine as regras sobre a ocupação do espaço, tanto na vida cotidiana quanto no tempo do carnaval. Felipe Ferreira (2005) discute, exaustivamente, em seu livro Inventando carnavais: o surgimento do carnaval carioca no século XIX e outras questões carnavalescas a luta pela ocupação do espaço e pela imposição de uma nova concepção de festa carnavalesca. Mostra de modo detalhado o processo de desqualificação do entrudo que, ligado pela memória ao passado colonial, precisará ser superado pela força da civilização, isto é, por

"um novo carnaval que, pelo menos conceitualmente, se adaptasse ao gosto e às necessidades da classe dominante emergente" (p. 39).

Nas décadas de 1960 e 1970, durante a implantação do projeto de modernização autoritária, novas pautas e novos valores interferem no espaço do carnaval. É possível verificar, nesse período, um esvaziamento das ruas promovido, em parte, pela implementação de políticas públicas que levam à criação de um circuito de desfiles para uma série de blocos tradicionais. Os blocos Bafo da Onça, Cacique de Ramos, Boêmios de Irajá, por exemplo, vão aos poucos deixando de desfilar em seus territórios de origem, em 
tendência ao desenraizamento. Já no mundo das escolas de samba, José Sávio Leopoldi (2010) registra aquilo que denomina processo de domesticação.

Entende que é resultado da submissão aos rigores da "ordem, da disciplina, da homogeneidade, ou seja, de tudo aquilo que caracteriza um espetáculo de grandes proporções a ser apreciado em escala nacional e mesmo mundial" ( $p$. 330). Esses dispositivos de disciplinamento contribuem para que alguns atores decretem a morte do carnaval como folguedo espontâneo.

Contemporaneamente, essa ideia de ordem se projeta mais uma vez sobre o carnaval de rua. No dia 9 de maio de 2009, a prefeitura define, via decreto, as regras para o Carnaval de 2010. No mesmo dia, o prefeito e os secretários municipais de Turismo e da Cultura participam da mesa de abertura do segundo Desenrolando a Serpentina, seminário promovido pela Associação Sebastiana para pensar, conforme explicita sua ata de fundação, o crescimento do carnaval de rua. A presença do poder público no seminário marca uma nova relação entre esse poder e os "sujeitos celebrantes", isto é, as pessoas que são capazes de liderar e organizar o processo festivo, definindo seus rumos e seus próprios elementos rituais (FERNANDES, 2001). Durante os anos em que os blocos da retomada vão construindo sua identidade, o silêncio e a ausência do poder público foram reveladores da incomunicabilidade entre esse poder e as ruas.

O novo decreto causou receio e incerteza, pois, embora o "choque de ordem" tivesse sido ressignificado como "choque de folia" pelo próprio prefeito nesse mesmo seminário, a desconfiança era oriunda das lembranças das diversas tentativas de implantação da ordem em nossa história republicana.

Em novembro de 2009, a prefeitura publicou a lista de 461 blocos que tiveram suas solicitações de desfile aprovadas - 39 na Zona Oeste, 54 na Barra da Tijuca e Recreio, 55 na Tijuca, 83 na Zona Norte, 96 no Centro da cidade, e 172 na Zona Sul. Os dados desmembrados por áreas geográficas permitem perceber que o movimento, inicialmente restrito à Zona Sul da cidade, foi-se espalhando pela malha urbana e revela a existência de um sistema de crenças, valores e comportamentos que nos últimos anos instauraram, como ensina Durkheim (1999), um fato social, isto é, "maneiras de agir, de pensar e sentir, capazes de exercer sobre o indivíduo uma coerção exterior". Coerção social que nos ajuda a entender o aumento do número tanto de foliões quanto de blocos carnavalescas dos mais diversos tipos, tamanhos e estilos.

A notícia a respeito da liberação dos desfiles, esperada com apreensão e ansiedade, tinha orientado diversas leituras. Para alguns blocos, o decreto 
que entrou em vigor no mês de maio poderia trazer restrições, proibições e indeferimento das solicitações realizadas. Outros entendiam que o crescimento do carnaval exigia algumas medidas organizativas que permitissem minimizar ou equacionar os problemas resultantes. Outros, ainda, sustentavam que o "espaço público é livre" e que as manifestações carnavalescas não precisam de organização, nem regulamentação, do poder público. Esta última posição foi defendida pela Desliga dos Blocos Carnavalescos, criada em resposta ao decreto municipal publicado no mês de maio e, também, ao que consideraram excesso de institucionalização, tanto da Sebastiana quanto da Associação Folia Carioca. ${ }^{5}$ A desliga carnavalesca promoveu uma "bloqueata", às vésperas do prazo final para solicitar autorização aos desfiles do Carnaval de 2010. Em documento veiculado nas redes sociais, seus membros informam que não têm a intenção "promover bagunça", mas entendem que "o excesso de normatização pode acabar com a espontaneidade dos blocos de carnaval" e reivindicam:

Cair na folia com o povo no meio da rua, cantar hinos e marchinhas a plenos pulmões, criar nossos roteiros ao sabor do acaso e da vontade dos participantes, estimular o livre dançar e aproveitar a meIhor época do ano na cidade do Rio. E principalmente, queremos ter assegurada a liberdade de ter ideias novas e colocá-las em prática na véspera do carnaval, afinal boa parte da graça de pular em blocos consiste no inusitado de ideias que podem surgir no calor do verão, em meio aos ensaios e batucadas de esquenta. ${ }^{6}$

Talvez, o "inusitado de ideias" diga respeito à possibilidade de criar novas agremiações para marcar presença no carnaval do ano, em meio aos "ensaios e batucadas do esquenta". Esse registro é compartilhado pelos sujeitos que participam ativamente das manifestações carnavalescas. São foliões que podem ser identificados com facilidade brincando em inúmeros blocos da cidade durante o reinado de Momo. Brincantes de todos os blocos, dos blocos da Sebastiana, dos que formaram a Folia Carioca, dos blocos da Desliga e até dos blocos sem liga. Trata-se, em termos weberianos, de uma ação social com relação a valores colocados com intensidade na negociação em torno do carnaval, que se apresenta assim como arena na qual se disputam, de modo sempre problemático, as diversas interpretações e tentativas de regulamentar o evento. O registro histórico do processo de construção e consolidação do carnaval moderno está repleto de histórias que pontuaram e pontuam o conflito entre diversas orientações e valores sociais e culturais. 


\section{O CONTEXTO DOS BLOCOS DA RETOMADA CARNAVALESCA}

Descrito o cenário, impõe-se qualificar o que denominamos "retomada do carnaval" de rua e apresentar informações que permitam esclarecer o quem, o como e o quando dessas "redes conflituosas de produção cultural" (MELUCCI, 1996).

O movimento da retomada foi, basicamente, constituído por atores da geração que participou da luta por uma sociedade igualitária nos anos 60 e 70, do século XX. No contexto do processo de democratização, se orientaram pelo desejo de ocupar o espaço público da rua até então interditado. Foi tomando forma nesse contexto a ideia de que a sociedade é constituída por cidadãos autônomos, responsáveis, portadores de direitos e obrigações que resultam de seu pertencimento a uma comunidade política.

As eleições para governador em 1982, com a vitória de muitos candidatos recém-chegados do exílio se inscrevem no registro da esperança e da politização. Registro que contagia e se projeta na campanha pelas eleições diretas para a Presidência da República. O movimento das Diretas Já representou a ruptura do silêncio, provocada pela multiplicidade de projetos e memórias que se apresentavam, nesse contexto, como possíveis. Processos semelhantes podem ser observados em outras realidades que também passaram por transição democrática acompanhada da revitalização das festas populares, de invenção e ou reinvenção de festas, de celebrações esquecidas ou perseguidas durante os períodos autoritários e que traduziam a vontade compartilhada de recuperação dos espaços públicos anteriormente interditados ${ }^{7}$.

A campanha pelas eleições diretas se transformou num movimento multitudinário, massivo, de ocupação do espaço público caracterizado por clima de celebração e festa. Essa dimensão é crucial, pois, como aponta Mikhail Bakhtin (1987) em A cultura popular na Idade Média e no Renascimento: o contexto de François Rabelais, as festas emanam do mundo dos ideais:

As festividades (qualquer que seja o seu tipo) são uma forma primordial, marcante, da civilização humana (...). As festividades tiveram sempre um conteúdo essencial, um sentido profundo, exprimiram sempre uma concepção de mundo. Os 'exercícios' de regulamentação e aperfeiçoamento do processo do trabalho coletivo, o 'jogo no trabalho', o descanso ou a trégua no trabalho nunca chegaram a ser verdadeiras festas. Para que o sejam, é preciso um ele- 
mento a mais, vindo de uma outra esfera da vida corrente, a do espírito e das ideias. A sua sanção deve emanar não do mundo dos meios e condições indispensáveis, mas daquele dos fins superiores da existência humana, isto é, do mundo dos ideais. Sem isso, não pode existir nenhum clima de festa (p. 7-8).

A intensa mobilização popular não foi suficiente para que o Congresso Nacional aprovasse a Emenda Constitucional Dante de Oliveira. Rapidamente, a euforia deu lugar a um sentimento generalizado de frustração, desencanto e, finalmente, de desmobilização. A desconfiança e o desinteresse pela participação política teve breve interrupção provocada quando da campanha pelo impeachment, na qual se verificou intensa participação social, particularmente da juventude.

Nesse episódio, boa parte da mídia tratou de recuperar a memória da participação política da juventude dos anos 70. Essa memória, porém, foi reconstruída de forma fragmentada. A tentativa de produzir aproximações entre um e outro contexto sempre excluiu a possibilidade de questionar ou de resgatar o que havia sucedido com aquela militância. Conforme sugere Pollak (1989), o papel da memória não é somente lembrar; trata-se de processo que pode recalcar, omitir ou recodificar dados do passado. Portanto, toda memória envolve um procedimento de construção da memória.

A recuperação de uma referência de "juventude mobilizada", que a mídia tratou de resgatar, deixou fora do universo rememorado o fato de que aquela juventude dos anos 60 e 70 lutava contra um Estado excludente e repressivo. Poderíamos dizer que, nesse novo contexto, a juventude "cara pintada" desempenhou, pelo grau de apropriação midiática que teve, o papel de estetização da política, como sugere Benjamin em seu ensaio A obra de arte na era de sua reprodutibilidade técnica (1996a).

A mobilização pró-impeachment alcançou seus objetivos, porém não foi suficiente para mudar um quadro que se projetou dramaticamente por toda a década de 1990. Década que viu aumentarem os índices de violência, e cujas políticas de controle foram orientadas pela lógica da "criminalização das camadas populares" (SILVA, 2004; ZALUAR, 2004). O diagnóstico principal foi o da construção de uma "cidade partida" (CARVALHO, 1994), dividida entre o mundo do asfalto e o mundo da favela. Portanto, o diagnóstico foi o de uma cidade imersa na incomunicabilidade, atemorizada pela violência cotidiana, cujos alvos principais foram as vítimas de sempre. 


\section{VALORIZAÇÃO DA FELICIDADE}

Nem tudo foi outono, nem rigoroso inverno. O verão, mais poético e seguramente mais profano, permitiu que alguns setores sociais tecessem outros relatos, que nos ajudam a identificar, como afirma Walter Benjamin (1996b) nas Teses sobre o conceito de história, modos de "escovar a história a contrapelo" (p. 225).

São muitos os atores que escrevem essa outra história, que ressignificam as leituras oficiais, que interrompem, mesmo que momentaneamente, o que Benjamin denomina cortejo triunfal dos poderosos (p. 225). Boa parte das letras dos sambas que animam os diferentes cortejos carnavalescos são um exemplo de criatividade na ressignificação da leitura institucionalizada do mundo e da história (das páginas dos livros didáticos, das matérias de jornal, da propaganda política, etc.). O movimento da retomada carnavalesca pode ser lido nesse sentido, e a noção de festa pode ajudar a compreender esse processo.

A festa, posto que em sua realização confluem determinadas vontades e projetos, se apresenta como um "produto social que expressa e reflete valores, crenças e interesses dos grupos que a protagonizam", e que a definem como uma "arena onde se desenrola uma ação coletiva especial, na qual uma comunidade dispersa, heterogênea e dividida se expressa com um grande sentido de unidade e comunhão" (VILARROYA apud. FERNANDES, 2001). Enquanto produto social, a festa é produtora de identidade entre os participantes, pois eles compartilham o "símbolo que é comemorado e que, portanto, se inscreve na memória coletiva como um ato emotivo, como a junção dos afetos e expectativas individuais, como um ponto em comum que define a interação dos participantes" (GUARINELLO, 2001).

Felipe Ferreira (2005) observa que é necessário refletir sobre a especificidade festiva do carnaval, relativizando a ideia de festa universal da inversão e do exagero. Ele propõe levar em consideração as forças que interagem "por meio de uma incessante disputa pelo espaço/poder marcados pelo lugar. Desse modo, assim como a festa se caracteriza na luta pela posse simbólica do lugar festivo, o carnaval se define como a luta pela posse simbólica do lugar carnavalesco" (p. 323). Essa perspectiva nos abre uma pista para pensar que, em 1984, com a criação do sambódromo, fica definido, pelo poder público, o lugar do carnaval. Paradoxal e paralelamente, 1984 é o ano do surgimento dos primeiros blocos da retomada, se propondo, como veremos a seguir, a ocupação da rua como espaço festivo e, também, como lugar do carnaval - o de rua, nesse momento, se configura como uma das opções, então bem pouco valorizada, 
em relação ao oficial. É importante chamar a atenção para o fato de que os atores que então decidem criar blocos de rua não têm um projeto claro, nem de ocupação, nem de mobilização, mas tão somente um desejo de desfrutar da liberdade e da alegria, proporcionada pelo encontro e celebração na rua. Talvez o que os mova seja um desejo inconsciente de recuperar o sentimento sutil de quem teve uma utopia e lutou por ela.

Utopia e ação transformadora estão na base do processo de desconstrução da visão da história sustentada pelos opressores, conforme discute Benjamin (1996b), nas Teses sobre o conceito de história. "Existe um encontro secreto, marcado entre as gerações precedentes e a nossa. Alguém na terra está à nossa espera. Nesse caso, como a cada geração, foi-nos concedida uma frágil força messiânica para o qual o passado dirige um apelo. Esse apelo não pode ser rejeitado impunemente"8 (p. 223).

A dimensão messiânica, presente na Segunda Tese, não significa contemplação. Pelo contrário, deve ser interpretada como dimensão essencialmente ativa que permite e conduz a uma atuação coletiva. "Nos aguardavam na terra para salvar do esquecimento aos derrotados, mas também para continuar e, se possível, consumar seu combate emancipatório" (BENJAMIN apud LöWY, 2002, p. 61).

A rua tem alma, informava João do Rio a seus leitores no início do século $X X$, registrando suas observações de uma cidade que passava por um processo acelerado de transformação modernizadora. Gostaríamos de propor que a "alma encantadora das ruas", outrora evocada pelo cronista carioca, começou a ser redesenhada no contexto da transição democrática por grupos sociais das camadas médias urbanas, particularmente dos bairros da Zona Sul da cidade. Foliões detentores de estreito vínculo com a militância dos anos 70 propõem uma recusa da desmobilização e abrem a possibilidade de contar outra história, que inclui a informalidade da brincadeira de rua, do riso e da ironia.

Na origem da recuperação do espaço público, de contestação e resistência que se vão projetar então na construção de outra imagem da cidade, se encontram o Bloco do Barbas, fundado no bairro de Botafogo e o Bloco Simpatia é Quase Amor, que desfila em Ipanema, ${ }^{9}$ ambos criados em 1984 . Este último foi batizado pela Banda de Ipanema. Comandada pelo célebre Albino Pinheiro, a Banda, desde sua criação em 1965, foi lida, pelos donos do poder (FAORO, 1958), como agremiação subversiva e conspiratória. ${ }^{10}$ Bebem dessa fonte os fundadores do Simpatia que, além disso, integravam, na campanha pelas eleições diretas, o Comitê Tancredo Neves, ligado ao antigo Movimento Democrático Brasileiro (MDB). Esse grupo participou ainda da torcida 
organizada, Fla-Diretas, composta, curiosamente, de vários torcedores de outros times da cidade, o que referenda o clima de festa e congraçamento. Com a derrota da luta pelas eleições diretas colocou-se uma questão prosaica: o que fazer dos instrumentos de percussão que animavam as ruas e as arquibancadas no processo de politização anterior? A sugestão de permanecer na rua, de continuar ocupando o espaço público, agora como mobilização carnavalesca, nos remete à reflexão arendtiana sobre a ação ao mostrar que "o ato de encontrar as palavras adequadas no momento certo, independentemente da informação que transmitem, constitui uma ação" (ARENDT, 1991, p. 35). E uma ação política também fala do inusitado, do imprevisível, do contingente e do indeterminado.

O Bloco do Barbas teve como sede social - em todos os sentidos - o bar e restaurante homônimo. Embora as redes sociais fossem as mesmas, os fundadores do Barbas desconheciam o desejo do pessoal do Simpatia de criar um bloco. O bar Barbas, no qual se originou o bloco foi, no início dos anos 80, ponto de encontro obrigatório de diversos grupos e instituições que, contagiados pelo clima de efervescência então reinante, se atreviam a pensar a cidade e o país. Bate-papo, conferências, lançamentos de livros, shows faziam parte da agenda do bar que também funcionou como ponte que integrou sambistas da velha e da "nova" tradição com o público da Zona Sul da cidade. Da "nova tradição" do samba fazem parte músicos e compositores reunidos em torno da tamarineira da quadra do tradicional bloco carnavalesco Cacique de Ramos $^{11}$ e que encontram, também, nesse novo lugar de sociabilidade, um espaço de divulgação e de formação de público.

Tanto o Simpatia quanto o Bloco do Barbas tiveram como inspiração, além do Cordão do Bola Preta, o Clube do Samba, bloco carnavalesco fundado em 1975 pelo cantor e compositor João Nogueira. O Clube do Samba é considerado por músicos, compositores e foliões "um dos mais belos quilombos de resistência cultural da nossa história" (PIMENTEL, 2002, p. 52).

Alargar as fronteiras do possível através da criação de um bloco carnavalesco foi sugestão do compositor Mauro Duarte, rapidamente incorporada por um coletivo quantitativa e qualitativamente significativo de foliões. ${ }^{12}$ Assim, como se a cidade estivesse saindo de uma profunda letargia e, para surpresa daqueles que tinham decretado, mais de uma vez, a morte do carnaval, veremos surgir em sequência outras manifestações similares orientadas pelo "enorme prazer de estar junto, de poder falar, de ocupar a rua". ${ }^{13}$ 
O Suvaco de Cristo, criado na primavera de 1985, terá que administrar, desde a origem, um conflito com a Cúria Metropolitana, que entende que Cristo não tem sovaco. ${ }^{14}$

O Bloco de Segunda, fundado, em 1987, por uma turma que também frequentava a praia de Ipanema e da qual faziam parte alguns ex-militantes do Movimento Revolucionário 8 de Outubro - MR8, terá seu batismo de fogo, para espanto de muitos, em seu desfile inaugural no dia 7 de setembro. Como esclarecem, com simplicidade inquestionável, duas das fundadoras do bloco, no documentário Os devotos do samba: 15 "afinal, se os militares vão às ruas para realizar a tradicional parada de comemoração do dia da independência, por que não os civis?" Claro que desfilaram com direito a repressão policial e ameaças de prisão.

Em 1991, foi fundado o Bloco das Carmelitas por uma rapaziada que frequentava um botequim vizinho ao Convento do qual, conforme a lenda, uma freira teria fugido, em tempos de carnaval, incorporando-se rapidamente à multidão fantasiada. A freira, desde então, virou ícone do bloco na figura de uma boneca gigante. Num de seus primeiros carnavais, segundo dizem seus fundadores, a Igreja católica, incomodada, teria acionado a polícia, cuja atitude foi dar voz de prisão à boneca.

O bloco Escravos da Mauá foi criado em 1993 e ocupa, desde então, o largo de São Francisco da Prainha, vizinho à Praça Mauá. O bloco vem desenvolvendo ao longo do ano importante trabalho de interação social com diversas comunidades da região portuária, hoje palco de disputa do projeto Porto Maravilha.

Meu Bem, Volto Já foi criado por ocasião das comemorações do centenário do bairro do Leme, em 1994, e apadrinhado pelo Bloco do Barbas, Simpatia e Bloco de Segunda. Segundo seu mito fundador, dom João VI, premido pelas forças de Napoleão no cerco de Lisboa, teria pronunciado, no convés do navio que o levaria a terras tropicais, a frase que dá nome ao bloco. ${ }^{16}$

Que Merda é Essa? surge em 1995, como pergunta frequente e recorrente em relação à maior parte das políticas públicas implementadas na cidade e no país. O Imprensa que eu Gamo aparece no mesmo ano. Foi inicialmente um bloco corporativo, inventado no calor da Caminhada pela Paz organizada por Herbert de Souza, o Betinho, e pelo Movimento Reage Rio, em novembro de 1994. Completam a lista dos blocos da Sebastiana o Ansiedade, bloco de frevo; o bloco Virtual, criado no momento da fundação da associação, e o bloco infantil Gigantes da Lira que desfila nas ruas do bairro de Laranjeiras.. 
Esses blocos, embora não exclusivamente, estão na base do processo de revitalização do carnaval de rua. Boa parte dos foliões e compositores transita com desenvoltura e irreverência por todos eles, constituindo uma rede particular de sociabilidade na qual se vislumbra preocupação que vai além das questões pautadas pelo carnaval, como, por exemplo, a preocupação de relativizar o paradigma da cidade partida. Uma rede que pode ser, nesse momento seminal, facilmente identificada com nome e sobrenome numa lista que não ultrapassaria 300 pessoas.

A ideia de festa, nesses segmentos, é essencial, e, como mostrou Bakhtin (1987, p. 240-241), a festa é base, fundamento essencial da civilização humana; "é a festa que, libertando de todo utilitarismo, de toda finalidade prática, fornece o meio de entrar temporariamente num universo utópico". Utopia no sentido de sonho, de projeto, de esperança, de transformação; no sentido estruturador de práticas sociais, como decantador de valores de mobilização e de ação social. Trata-se, não é demais enfatizar, de um movimento da sociedade civil, que canta, encanta e conta a história "a contrapelo", produzindo, em muitos casos, uma desconstrução daquilo que Vynies (2009, p. 25) define como "boa memória" do Estado.

Podemos encontrar esses mecanismos de desconstrução na definição dos enredos e nas escolhas dos sambas que serão cantados no cortejo. Essas músicas costumam narrar uma história que, geralmente, não compartilha das leituras e interpretações oficiais. Como dizem os representantes desses blocos, os diversos governos são "generosos", deixam à disposição temas que exigem, sempre, outra interpretação.

Gostaríamos de propor a ideia de que, nesse universo, os compositores assumem o papel do narrador que, como disse Benjamin (1996b, p. 201) "retira da experiência o que ele conta: sua própria experiência ou a relatada pelos outros. E incorpora as coisas narradas à experiência de seus ouvintes". O ouvinte/folião atua como sujeito, como participante e não como mero espectador. O leitor dessas crônicas urbanas, o brincante, é "livre para interpretar a história como quiser". Quem escuta e participa, cantando, vai exercendo sua sociabilidade nas relações de copresença, "em companhia do narrador". Reforçam nossos argumentos sambas que ajudaram a pentear a historia a contrapelo das comemorações oficiais dos 500 anos do descobrimento, ${ }^{17}$ ou por ocasião do centenário da República. ${ }^{18}$

Não gostaríamos de deixar de mencionar que essa rede de sociabilidade formada em torno dos desfiles dos novos blocos tem responsabilidade na transformação pela qual passou o tradicional bairro da Lapa. Local de encontro 
de malandragem e boemia nos anos 40 e 50, o bairro sofreu um processo de degradação dos 60 aos 80, e, a partir de meados da década de 1990, se inicia um processo de revitalização ainda em curso. A abertura do bar Coisa da Antiga - nos fundos de um antiquário na tradicional Rua do Lavradio - acabou sendo o catalisador e o formador de uma rede de foliões que vai inventando e conectando diversas festas e rodas de samba na cidade. Essa rede de foliões era facilmente encontrada nas diversas atividades institucionais promovidas pelos blocos. Frequentavam todos os ensaios, lançamentos de camisetas, escolhas de samba e, claro, todos os desfiles, num tempo em que era possível organizar a agenda.

O bar da Rua Lavradio 100 seguiu os passos do Mandrake, bar do bairro de Botafogo, que promoveu, entre 1985 e 1996, uma importante roda de samba. Foi ali, por exemplo, que surgiu o bloco carnavalesco Concentra mas Não Sai, organizado por Beth Carvalho, Paulinho Soares, Edmundo Souto, entre outros compositores. Como observa Felipe Trotta (2004, p.3), as rodas de samba são lugares de "expressão simbólica de uma visão de mundo", que permitem o desenvolvimento de "experiências musicais sociais" e se transformam em instâncias que "promovem a circulação de música pela sociedade, exercendo um papel de legitimação perante os repertórios utilizados nesses eventos".

Foi nas rodas mencionadas que os novos compositores dos blocos de carnaval foram costurando suas relações de parcerias. Parcerias que têm um elevado grau de instabilidade. Diferentemente dos compositores das escolas de samba tradicionais, que em geral pertencem a uma única escola, os compositores dos blocos transitam por todos eles, fazendo e refazendo parcerias orientadas, costumeiramente, pela disponibilidade de tempo para fazer o samba e concorrer. Como a disputa não é mediada pelo dinheiro, como a indústria fonográfica e a ideia de profissionalização não se encontram presentes, observa-se uma feliz "promiscuidade". Intentamos argumentar que também nesse universo o samba-enredo constitui, como propõe Maria Laura Cavalcanti (2006, p. 96), um lugar social "de ampla circulação de ideias, onde ecoam e são reinterpretados os mais diversos tópicos do imaginário social nacional".

\section{CONSIDERAÇÕES FINAIS}

Benjamin é pensador otimista cuja perspectiva crítica o leva a identificar, no presente, as possibilidades de realização dos desejos e das liberdades que resistem ao longo da história. Não se lança, portanto, na descrição do campo das impossibilidades. É otimista, mas não ingênuo, como podemos ver em diversos momentos de sua produção intelectual. Lamenta, entretanto, a força 
das manobras capitalistas para encobrir as brechas da nova ordem social ou para manipular, ressignificando, os desejos das massas de desfrutar de uma condição de vida mais livre e mais digna, na qual se valore a questão da felicidade, tema central em seu pensamento político. A felicidade, enquanto aspiração é, como aponta Katia Muricy (1988, p. 506), fator fundamental na concepção de ação política benjaminiana:

É este impulso de felicidade que nos remete ao passado, pois a imagem de felicidade relaciona-se à época a que pertencemos e que nos escapa (...). É o que poderia ter sido que mobiliza nosso desejo. A experiência de felicidade, a 'iluminação profana' está vinculada à salvação do passado. A tarefa da política 'arrancada das mãos profanas' não é a de construção do futuro, mas a de apropriação do passado - em função do presente.

O resultado não esperado dessa simbiose entre botequim, roda de samba e carnaval levou ao significativo crescimento do carnaval de rua. A percepção do crescimento fez com que os organizadores dos blocos aqui citados resolvessem pela criação de uma associação, a Sebastiana, que Ihes permitisse pensar e entender as novas realidades do carnaval, da rua e da cidade. Dessa nova realidade, participam hoje aproximadamente 500 blocos ligados a diferentes lugares e territórios. Essa multiplicidade de manifestações culturais recolocou uma série de questões relativas a disputas pela utilização do espaço, provocando impactos e dilemas, e abrindo novas perspectivas e oportunidades que ainda precisam ser devidamente avaliadas. Os questionamentos que se abrem a partir desses dados quantitativos sugerem a relevância política e social dessa nova manifestação cultural da cidade. ${ }^{19}$ Colocam, também, desafios aos formuladores de políticas públicas, assim como aos atores da sociedade civil que trabalham na realização desses eventos festivos.

O movimento dos blocos teve início como ação entre amigos, entre companheiros de militância, como ação social orientada por valores de solidariedade e defesa dos processos de participação política e cultural. Hoje, 28 anos depois, mobiliza quase 5,3 milhões de pessoas - jovens na maioria; muitas 're-conhecendo' sua cidade, exercitando a arte do flâneur, interditada em épocas de cidade dividida. Vislumbramos, nessa dobra da memória, um processo de construção de pontes que unem e desvendam a riqueza da pluralidade. Se o contato com o passado recente se encontra blindado, a festa parece ser um caminho que conduz à possibilidade de experimentar coletivamente a cidade como própria, enfatizando a importância de reconhecer a existência da ordem dos desejos. 


\section{REFERÊNCIAS BIBLIOGRÁFICAS}

ARENDT, Hannah. A condição humana. Rio de Janeiro: Forense Universitária, 1991.

BAKHTIN, Mikhail. A cultura popular na Idade Média e no Renascimento. São Paulo: Hucitec/UnB, 1987.

BENJAMIN, Walter. A obra de arte na era de sua reprodutibilidade técnica. In Obras Escolhidas. V. I. São Paulo: Brasiliense, 1996a.

. Teses sobre o conceito de história. In Obras Escolhidas. V. I. São Paulo: Brasiliense, 1996b.

CARVALHO, Maria Alice Rezende. Quatro vezes cidade. Rio de Janeiro: Sette Letras, 1994.

CARVALHO, Rafael Dummar Magalhães. A criação, transmissão e aprendizado informal de músico dentro da bateria de um bloco de carnaval. Monografia de final de curso, apresentada no Centro de Letras e Artes do Instituto VillaLobos - UNIRIO, 2010.

CAVALCANTI, Maria Laura. Carnaval carioca: dos bastidores ao desfile. Rio de Janeiro: Editora UFRJ, 2006.

CRUELLS, Adrià Pujol. Ciudad, fiesta y poder en el mundo contemporáneo. Liminar. Estudios Sociales y Humanísticos. San Cristóbal de las Casas: Universidad de Ciencias y Artes de Chiapas, v. 2, p. 36-49, diciembre 2006.

DURKHEIM, E. As regras do método sociológico. São Paulo: Martins Fontes, 1999.

FAORO, Raymundo. Os donos do poder. Formação do patronato político brasileiro. Porto Alegre: Ed. Globo, 1958.

FERNANDES, Nelson da Nóbrega. Escolas de samba: sujeitos celebrantes e objetos celebrados. Rio de Janeiro: Secretaria das Culturas. Departamento Geral de Documentação e Informação Cultural, Arquivo Geral da Cidade do Rio de Janeiro, 2001.

FERNANDES, Rita. Poluição Azul. O Globo, Rio de Janeiro, 7 mar. 2012, Opinião, p. 7.

FERREIRA, Felipe. Inventando carnavais: o surgimento do carnaval carioca no século XIX e outras questões carnavalescas. Rio de Janeiro: Editora UFRJ, 2005.

FORTUNA, Carlos; SILVA, Augusto Santos. A cidade do lado da cultura: espacialidades sociais e modalidades de intermediação cultural. In SANTOS, Boaventura de Sousa (org.). A globalização e as ciências sociais. 2.ed. São Paulo: Cortez, 2002.

GUARINELLO, N. L. Festa, trabalho e cotidiano. In: JANCSO, Istvan; KANTOR, Iris (orgs.). Festa: cultura e sociabilidade na América portuguesa. V. 2, p. 969975. São Paulo: Edusp/Hucitec, 2001.

LEFEBVRE, Henry. O direito à cidade. São Paulo: Editora Moraes Ltda, 1991. 
LEOPOLDI, José Sávio. Escolas de samba, blocos e o renascimento da carnavalização. Textos escolhidos de cultura e arte populares, Rio de Janeiro, v.7, n.2, p. 27-44, nov. 2010.

LÖWY, Michel. Walter Benjamin: aviso de incendio. Buenos Aires: Fondo de Cultura Economica de Argentina S.A, 2002.

MELUCCI, Alberto. Juventude, tempo e movimentos sociais. Young, Estocolmo, v. 4, n. 2, p. 3-14, 1996.

MURICY, Katia. Benjamin: política e paixão. In Os sentidos da paixão. São Paulo: Companhia das Letras, 1988.

PEREIRA, Carlos Alberto Messeder. Cacique de Ramos: uma história que deu certo. E-papers, 2003.

PIMENTEL, João. Blocos: uma história informal do carnaval de rua. Rio de Janeiro: Relume Dumará. 2002.

POLLAK, Michael. Memória, esquecimento, silêncio. Estudos Históricos, Rio de Janeiro: CPDOC/FGV, v.2, n.3, 1989.

SEVCENKO, Nicolau. Literatura como missão: tensões e criação cultural na Primeira República. São Paulo: Brasiliense, 1983.

SILVA, Luiz Antônio Machado da. Sociabilidade violenta: por uma interpretação da criminalidade contemporânea no Brasil urbano. In RIBEIRO, L.C. de Queiroz (org.). Metrópoles: entre a cooperação e o conflito. São Paulo/Rio de Janeiro: Perseu Abramo/Fase, 2004.

TROTTA, Felipe da Costa. Entre o Candongueiro e o Canecão: os espaços do samba na indústria da cultura. Trabalho apresentado no V Congresso Latinoamericano da Associação Internacional para o Estudo da Música Popular, IASPM- LA. Rio de Janeiro, 21 a 25 de junho de 2004.

VALLADARES, Licia. Cem anos pensando a pobreza (urbana) no Brasil. In Corporativismo e Desigualdade: a construção do espaço público no Brasil. Org. BOSCHI, Renato R. Rio de Janeiro: Rio Fundo Editora/luperj. 1991.

VINYES, Ricard. La memoria del Estado. In: LAMBRÉ, Tomás Lambré (coord.). Estado y la memoria. Buenos Aires: Del Nuevo Extremo: RBA (España), 2009.

ZALUAR, Alba. Integração perversa: pobreza e tráfico de drogas. Rio de Janeiro: Editora FGV, 2004.

\section{NOTAS}

1 Cf. artigo de Rita Fernandez (7.3.2012), presidente da Associação Sebastiana, de blocos da Zona Sul do Rio de Janeiro; ver nota 3.

2 Quase 300 jovens foram detidos no Carnaval de 2011 e enquadrados no artigo 233 do Código Penal: praticar ato obsceno em via pública. Cf. O Globo, 22.2.2011. 
3 Integram a Associação Sebastiana 12 blocos criados entre 1984 e 1996 e que estabeleceram um sistema de apadrinhamentos múltiplos num tempo em que ainda era possível organizar a agenda carnavalesca. Ver www.sebastiana.org.br

4 "sirven para que afloren las contradicciones y los antagonismos, el fondo de lucha y de conflicto que en condiciones cotidianas apenas llega a vislumbrase. He aquí por qué la arena festiva resulta tan adecuada a fin de contemplar cuáles son las relaciones de poder en una sociedad, cómo interactuán principios ideológicos, concepciones del pasado con proyectos de futuro que son, por definición, incompatibles, y que conviven posponiendo su permanente tendencia al enfrentamiento". A tradução é nossa.

5 No mês de agosto de 2009, 22 blocos e bandas da Zona Sul, Centro e Zona Norte do Rio de Janeiro fundaram a Associação Folia Carioca. Cf. www.bafafa.com.br

6 Agenda do Samba e Choro (http://www.samba-choro.com.br/), 25.8.2009.

7 Para o caso de Portugal, ver Fortuna e Silva, 2002.

8 "Nos aguardavam na terra para salvar do esquecimento aos derrotados, mas também para continuar e, de ser possível, consumar seu combate emancipatório". A tradução é nossa.

9 Uma história desses blocos de carnaval se encontra no trabalho do folião, jornalista e compositor João Pimentel (2002).

10 A enigmática inscrição "Yolhesman Crisbeles", estampada na faixa da comissão de frente da Banda, embora destituída de qualquer sentido, era interpretada pelos agentes da ordem como um código secreto e conspiratório.

11 Sobre a relação entre o samba e o Cacique de Ramos, ver Pereira, 2003.

12 Da reunião de formação do bloco do Barbas participaram aproximadamente 80 pessoas. Nelson Rodrigues Filho, Mauro Duarte, Cristina Buarque, Beth Carvalho, Noca da Portela, Afonso Celso Garcia Reis - Afonsinho, Luis Francisco de Almeida - Lefê, este último responsável pelo movimento de revitalização da Lapa.

13 Depoimento, dado aos autores, em junho de 2011, por Claudio Lobato, um dos fundadores do bloco O Charme da Simpatia, criado em 1975, num momento de ausência do carnaval de rua e de esvaziamento da cidade. O bloco deu origem ao movimento de poesia marginal Nuvem Cigana. O Charme da Simpatia e o Nuvem Cigana estão na origem do bloco Suvaco de Cristo, criado em 1986.

14 Sobre as origens do bloco Suvaco de Cristo, consultar Carvalho, 2010.

15 Disponível em : http://www.youtube.com/watch?v=T2qy-jD_x7cpartel e em http://www.youtube.com/watch?v=ATRyvgn70x8\&feature=related parte II

16 Sobre o mito fundador do bloco Meu Bem, Volto Já, cf. http://www.sambachoro.com.br/ acessado em 14 de janeiro de 2008. 
17 Como o samba de Lefê, Marceu e Janjão para o bloco Meu Bem, Volto Já.: "Ouvi o grito de Ipiranga/vi o general da banda/abolindo a escravidão/abraçado com a mulata/o Zumbi saiu da mata/Conselheiro do sertão/eu volto já meu bem não leve a mal/entrudo abunda no país do carnaval..."

18 O samba de Lenine feito em 1989 para o bloco Suvaco de Cristo se encaixa nessa perspectiva: "República dos vira-latas/das concordatas/do economês/ República do golpe baixo, do deixa-disso, é muito escracho com a cara de vocês/ se não melhorar eu vou vender goma de mascar/ numa rua de Moscou."

19 A festa de rua, enquanto um dos elos da cadeia produtiva da economia do carnaval movimentou um bilhão de reais em 2011. Segundo a Riotur, entraram na cidade 750 mil turistas -70 mil a mais do que o esperado pelas mais otimistas previsões. Houve, no período, diminuição de $28 \%$ de acidentes, em relação ao ano anterior. Não há, aliás, registro de acidentes graves, numa festa que congrega 3,5 milhões de pessoas no espaço público, durante uma semana.

Jorge Edgardo Sapia é cientista social pela UFF, mestre em sociologia pelo Instituto Universitário de Pesquisas do Rio de Janeiro - luperj, professor temporário da UFRRJ, professor do Curso de Comunicação Social e de História da Universidade Estácio de Sá (Unesa), professor da Pós-Graduação/Especialização Lato Sensu - Carnaval e Cultura - Unesa, lecionando a disciplina teoria social do carnaval.

Andréa Almeida de Moura Estevão é jornalista, mestre em comunicação e cultura pela ECO/UFRJ, professora da Pós-Graduação/Especialização Lato Sensu em jornalismo cultural e da Pós-Graduação/Especialização Lato Sensu - Carnaval e Cultura da Unesa. Organizadora do livro Comunicação e imagem, publicado em 2006 pela Editora Rio. 